\title{
Mean Changes in Sperm Count in Adult Males after Varicocelectomy
}

\author{
MOHIB ULLAH ${ }^{1}$, IBRAHIM AHMED ${ }^{2}$, SANA ULLAH ${ }^{3}$, SAMI UR REHMAN ${ }^{4}$, ASIF KHAN ${ }^{5}$, MUHAMMAD ALI SHAH ${ }^{6}$ \\ ${ }^{1}$ District Specialist Urology Nawaz Sharif Kidney Hospital, Swat \\ 2,3,4 Medical Officer Urology Nawaz Sharif Kidney Hospital, Swat \\ ${ }_{5,6}$ Medical Officer Urology Saidu Group of Teaching Hospitals, Swat \\ Corresponding author: Dr. Mohib Ullah, Email: Mohaibkhan751@gmail.com, Contact No.+92 3489304998
}

\begin{abstract}
Background: Varicocele, a bilateral vascular condition in which hypoxia can induce ischemic damage to both testes due to hydrostatic pressures in the venous drainage system, is a prominent cause of male infertility with a complex pathogenesis. varicocele make up $35 \%$ of primary infertility and $81 \%$ of secondary fertility.

Methodology: A quasi-experimental study was conducted from January 2018 to September 2018 at urology department of Nawaz Sharif Kidney Hospital and Saidu Group of Teaching Hospitals, Swat. Sample size was 261. The study included all males between the ages of 20 and 60 who had clinically evident varicocele.

Result: Results of our study P-value for pre-operative and post-operative sperm count was 0.00001 so statistically significant. According to the age distribution, 93 patients were in the age group 20-30 (35.63\%), 70 patients in age group 31-40 years (27.01\%), 60 patients aged 41-50 (22.98\%), 38 patients aged 51 to 60 (14.26) $\%)$ are shown in Table 2 . All cases had varicocele on the left side.

Conclusion: After inguinal varicocelectomy, sperm count increases in adult patients with clinically palpable varicocele.
\end{abstract}

Keywords: Adult male, Sperm count, Varicocele, Varicocelectomy.

\section{INTRODUCTION}

Varicocele is one of the major known cause of infertility in men but can be treated $(1,2)$. Varicocele, a bilateral vascular condition in which hypoxia can induce ischemic damage to both testes due to hydrostatic pressures in the venous drainage system, is a prominent cause of male infertility with a complex pathogenesis. $(3,4)$. Varicocele affects nearly a third of infertile guys, with a frequency of roughly $15 \%$ in the general male population. (5). Enlargement of testicle veins or varicocele make up $35 \%$ of primary infertility and $81 \%$ of secondary fertility. (6.7)

Clinical and subclinical are two types of varicocele $(8,9)$. Subclinical varicocele is considered asymptomatic varicocele that can't be touched or seen at rest or during Valsalva maneuvers, but can be diagnosed though Doppler ultrasound (10). Clinical venous varicose veins are divided into three classes: the first level can be touched only when the Valsalva movement is shown, the second level is touchable but not visible at rest. You can see and touch 3rd degree varicocele (11). Two recent meta-analyses have found that surgical removal of enlarged testicular veins significantly improved sperm concentration and motility in fertile men with palpable enlarged veins and abnormal sperm parameters before surgery, and increased the likelihood of spontaneous pregnancy. $(12,13)$. The method of treatment depends on professionalism, the presence of scars from previous surgeries and the availability of technical facilities. High retroperitoneal or translingual approaches can be used, the latter being common in these areas (12).

Objective of the study was to find out change in sperm count after the management of varicocele (enlarged testicular veins) as this type of study is not conducted in the primases of Khyber-Pakhtunkhwa.

\section{METHODOLOGY}

A quasi-experimental study was conducted from January 2018 to September 2018 (for 9 months duration) at urology department of Nawaz Sharif Kidney Hospital and Saidu Group of Teaching Hospitals, Swat. With a 95\% confidence interval the sample size was 261 . The study included all males between the ages of 20 and 60 who had clinically evident varicocele. Clinical examination and scrotal ultrasonography ruled out all other causes of scrotal enlargement, including hydrocele, haematocele, pyocele, recurrent varicocele, and inguino-scrotal hernia. Ethical approval was taken from hospital research and ethical committee. In the surgical outpatient department, patients who met the inclusion criteria were chosen.

Patients gave their informed written agreement to participate in the study. The unit's senior postgraduate resident gathered and recorded patient data into a semistructured proforma. A comprehensive history was collected and an examination was performed. To rule out other causes of scrotal enlargement and reduce personal bias, an ultrasound was conducted by a single consultant with a fellowship in radiology from the hospital radiology department. To reduce sampling bias, sperm samples were taken from diagnosed patients in a secluded place by selfstimulation at body temperature (370C / 98.6 OF) and evaluated by a single laboratory technician using the same methodology 30 minutes after ejaculation. The information was stored in a password-protected digital database. The patient was prepped for surgery in the ward, and informed consent was obtained following a thorough explanation of the treatment and its risks. Inguinal varicocelectomy was performed on all of the patients. The inguinal ligament was incised one and a half centimeter above and horizontally. External oblique aponeurosis was severed from superficial inguinal ring to deep inguinal ring after soft tissue dissection. The illio inguinal nerve was discovered and saved. The spermatic cord was cut out, and the spermatic vein and any tributaries were identified. The spermatic artery was identified using Doppler ultrasonography. Vicryl two zero was used to ligate and split the spermatic vein and its tributaries. All cases were closed anatomically layer by layer to ensure hemostasis. Patients were checked 
every ten days for wounds and every six months for sperm analysis. The data was analysed using SPSS 20.0, a statistical software for social sciences. The mean SD was computed for quantitative variables such as age, varicocele duration, pre-operative sperm count, and post-operative sperm count. Qualitative variables such as varicocele grades were provided as percentages and frequencies. The mean pre-operative and post-operative sperm counts were compared using a paired t-test, with a $P$ value of 0.05 considered significant. To examine if there was any effect modification, sperm count was stratified by grade, age, and duration of varicocele. A paired $\mathrm{T}$ test was used after stratification, with a $P$ value of 0.05 considered significant.

\section{RESULTS}

According to the results of our study P-value for preoperative and post-operative sperm count was 0.00001 so statistically significant. Mean and standard deviation for pre and post-operative sperm count was $16 \pm 18.003$ million and $33 \pm 14.156$ million respectively. Results were shown in table 01 . According to the age distribution, 93 patients were in the age group $20-30(35.63 \%), 70$ patients in age group 31-40 years (27.01\%), 60 patients aged 41-50 (22.98\%), 38 patients aged 51 to $60(14.26) \%$ ) are shown in Table 2. All cases had varicocele on the left side. The prevalence and percentage of varicocele in grade I was recorded among 27 patients (10.34\%), 126 grade II patients $(48.27 \%)$ and 108 grade III patients $(41.37 \%)$ (Table 3).

Table 1: Mean change in pre-op and post-operative sperm count. $(\mathrm{n}=261)$

\begin{tabular}{|l|l|l|}
\hline Mean and SD & Sperm Count & P Value \\
\hline $\begin{array}{l}\text { Pre-operative sperm } \\
\text { count }\end{array}$ & $16+18.003$ million & \\
\cline { 1 - 2 } $\begin{array}{l}\text { Post-operative sperm } \\
\text { count }\end{array}$ & $33+14.156$ million & \multirow{2}{*}{$0.00001^{*}$} \\
\cline { 1 - 2 } Mean Change & $6+10.023$ million & \\
\hline
\end{tabular}

Table 2: Stratification of sperm count with respect to age $(n=261)$

\begin{tabular}{|c|c|c|c|c|}
\hline & \multirow[b]{2}{*}{ Sperm Count } & \multicolumn{2}{|c|}{ Frequency \& Percentages } & \multirow[b]{2}{*}{$\mathrm{P}$ Value } \\
\hline Age & & \multicolumn{2}{|c|}{ |l } & \\
\hline & & Pre-operative & Post-Operative & \\
\hline \multirow{3}{*}{ 20-30 Years } & $<30$ Million & $37(14.36 \%)$ & $18(6.89 \%)$ & \multirow{2}{*}{0.00001} \\
\hline & & & & \\
\hline & $>30$ Million & $56(21.26 \%)$ & $75(28.73 \%)$ & \\
\hline \multirow{3}{*}{$31-40$ Years } & $<30$ Million & $51(19.54 \%)$ & $46(17.81 \%)$ & \multirow{3}{*}{0.00001} \\
\hline & & & & \\
\hline & > 30 Million & $19(7.47 \%)$ & $24(9.19 \%)$ & \\
\hline \multirow{3}{*}{ 41-50 Years } & $<30$ Million & $51(19.88 \%)$ & $46(17.81 \%)$ & \multirow[b]{2}{*}{0.00001} \\
\hline & & & & \\
\hline & $>30$ Million & 09 (3.44\%) & $14(5.17 \%)$ & \\
\hline \multirow{3}{*}{ 51-60 Years } & $<30$ Million & $05(1.92 \%)$ & $23(8.82 \%)$ & \multirow{3}{*}{0.00001} \\
\hline & & & & \\
\hline & $>30$ Million & $33(12.64 \%)$ & $15(5.74 \%)$ & \\
\hline
\end{tabular}

Table 3: Stratification of sperm count with respect to grades of varicocele $(\mathrm{N}=261)$

\begin{tabular}{|c|c|c|c|c|}
\hline \multirow{2}{*}{$\begin{array}{l}\text { Grades of } \\
\text { Varicocele }\end{array}$} & \multirow{2}{*}{ Sperm Count } & \multicolumn{2}{|c|}{ Frequency \& Percentages } & \multirow[b]{2}{*}{ P Value } \\
\hline & & Pre-operative & Post-Operative & \\
\hline \multirow{3}{*}{ Grade I } & $<30$ Million & $06(2.29 \%)$ & $01(0.57 \%)$ & \multirow{3}{*}{0.00001} \\
\hline & & & & \\
\hline & $>30$ Million & $21(8.04 \%)$ & $26(9.77 \%)$ & \\
\hline \multirow{3}{*}{ Grade II } & $<30$ Million & $43(16.66 \%)$ & $24(9.19 \%)$ & \multirow{3}{*}{0.00001} \\
\hline & & & & \\
\hline & > 30 Million & $83(31.60 \%)$ & $102(39.08) \%$ & \\
\hline \multirow{3}{*}{ Grade III } & $<30$ Million & $99(37.93 \%)$ & $81(31.03 \%)$ & \multirow{3}{*}{0.00001} \\
\hline & & & & \\
\hline & > 30 Million & 09 (3.44\%) & $27(10.34 \%)$ & \\
\hline
\end{tabular}

\section{DISCUSSION}

Varicocele repair has been a controversial issue for decades. However, when sperm counts were compared before and after intervention, there was an increase in sperm counts after varicose embolism (11). Based on current information and research results, it can be concluded that fertility is causally associated with palpable varicocele in older male patients (12). Varicocele are associated with excessive damage to the genetic material in the sperm nuclei, reversible by incision of enlarged veins, as evidenced by a number of studies supporting our findings (14).
In contrast, as noted in the Cochrane database review in 2009 (15), there is no evidence that varicose vein repair is associated with an increased risk of binary insemination.

A recent meta-analysis of venous varicose veins showed that adult men with venous varicose veins and autism in a tangible process had better results after surgical intervention, and supported our study. A global odds ratio of 2.23 (95\% confidence interval [Cl], 0.86, 5.78; $p=0.091$ ) indicates that although the difference is not statistically significant, surgical treatment is the preferred method (16). The 2009 Cochrane database review has several technical weaknesses, including some 
heterogeneous articles, with men with the highest sperm count and men with asymptomatic subclinical enlargement of testicular veins or varicocele (17). Subclinical varicocele were not included in our study. In addition, the nearexperimental design of this study prevents biases related to the effects of other hormones on sperm count, like FSH Hormone levels were the same before and after the intervention compared using paired t test. A review of the literature found that 15 out of 22 studies support our results. That is, the sperm count increased significantly after varicose vein repair. Results from the remaining seven studies can be attributed to heterogeneity in patient characteristics $(18,19)$. In a randomized controlled trial by Abdel-Meguid TA, a model of 145 candidates was followed up for one year. $13.9 \%$ of the untreated group had spontaneous pregnancies and $32.9 \%$ of the treated group (odds ratio, 3.04).

Following follow-up, significant improvements in pregnancy rates and sperm counts were reported ( $p$ $<0.0001$ ) (20). Similar results were obtained in our study compared to this study, in which also sperm parameters increased significantly and the number of sperm was less than 15. Million / $\mathrm{ml}(\mathrm{p}<0.00001)$. Given this randomized controlled trial, surgical treatment is better than nonsurgical treatment in patients with second- or third-degree varicocele and low sperm count. In another study, Najari et al. examined a total of 30 patients. One group had 17 infertile patients and other group had 13 patients with palpable varicoceles as well as low sex hormones levels. Out of these, 15 patients (44\%) showed increased libido while $18(53 \%)$ showed increased ejaculation volume. Blood testosterone levels improved $136.0 \pm 201.3 \mathrm{ng} / \mathrm{dL}$ (21) which as compared to our study where in grade III, $108(41.37 \%)$ patients were recorded and as the sperm count rose significantly with a mean change of $6 \pm 10.023$ million. One group had 17 fertile patients and the other group had 13 patients with palpable varicocele and low sex hormone levels. Of these, 15 (44\%) increased libido and 18 (53\%) increased ejaculation. Compared to our study, blood testosterone levels increased by $136.0 \pm 201.3 \mathrm{ng} / \mathrm{dL}(21)$, of which 108 (41.37\%) patients were enrolled in grade III, resulting in a significant increase in sperm count, with a mean change of $6 \pm 10.023$ million.

Although the sample size is reasonable, the strength of this study lies in its design. Although this is a semiexperimental study, it actually establishes a linear relationship between the variables of interest before and after the intervention.

\section{REFERENCES}

1. Etiologic factors in 1294 consecutive cases of male infertility. WHO. Fertil Steril, 22: 469, 1971

2. 2. Schlesinger, M. H., Wilets, I. F. and Nagler, H. M.: Treatment outcome after varicocelectomy. A critical analysis. Urol Clin North Am, 21: 517, 1994
3. Gat Y, Zukerman Z, Chakraborty J, Gornish M. Varicocele, hypoxia and male infertility. Fluid mechanics analysis of the impaired testicular venous drainage system. Hum Reprod. 2005;20:2614-2619

4. Ghabili K, Shoja MM, Agutter PS, Agarwal A. Hypothesis: intracellular acidification contributes to infertility in varicocele. Fertil Steril. 2009;92:399-401

5. Nagler, H. M., Luntz, R. K. and Martinis, F. G.: Varicocele. In: Infertility in the Male, 3rd ed. Edited by L. I. Lipshultz and S. S. Howards. St. Louis: Mosby-Year Book, p. 336, 1997

6. Meacham RB, Townsend RR, Rademacher D, Drose JA. The incidence of varicoceles in the general population when evaluated by physical examination, gray scale sonography and color Doppler sonography. J Urol. 1994;151:1535-1538.

7. Gorelick JI, Goldstein M. Loss of fertility in men with varicocele. Fertil Steril. 1993;59:613-616.

8. Goel B, Pathak K, Khan NA, Abid M. Varicocele: An Overview. International Journal of Pharmacy \& Life Sciences. 2013;4:2840-4.

9. Pastuszak AW, Wang R. Varicocele and testicular function. Asian journal of andrology. 2015;17:659.

10. Krishna Reddy SV. Varicocele and male infertility: Current issues in management-A Review. Med Surg Urol. 2014;3:137-42.

11. Prasivoravong et al: Beneficial effects of varicocele embolization on semen parameters. Basic and Clinical andrology. 2014;24;9

12. Agarwal A, Deepinder F, Cocuzza M et al: Efficacy of varicocelectomy in improving semen parameters: new metaanalytical approach. Urology 2007; 70: 532.

13. Marmar JL, Agarwal A, Prabakaran S et al: Reassessing the value of varicocelectomy as a treatment for male subfertility with a new metaanalysis. Fertil Steril 2007; 88: 639

14. Zini A, Dohle G. Are varicoceles associated with increased deoxyribonucleic acid fragmentation? FertilS teril 2011 ;96:1283-7.

15. Evers JH, Collins J, Clarke J. Surgery or embolization for varicoceles in subfertile men. Chochrane Database Syst Rev. 2012;18.

16. Zhou T, Zhang W, Chen Q, Li L, Cao H, Xu CL, Chen GH, Sun $\mathrm{YH}$. Effect of varicocelectomy on testis volume and semen parameters in adolescents: a meta-analysis. Asian journal of andrology. 2015;17:1012.

17. FicarraV, Currato MA, Iguori $G$ et al.Treatment of varicocele in subfertile men:The chochrane review-A contrary opinion. Euro Urol 2011;49:258-63.

18. Baazeem A, Belzile E, Ciampi A, Dohle G, Jarvi K, Salonia A, Weidner W, Zini A. Varicocele and male factor infertility treatment: a new meta-analysis and review of the role of varicocele repair. European urology. 2011;60:796-808.

19. Nevoux $P$, Mitchell V, Chevallier D et al: Variococele repair: does it still have a role in infertility treatment? Curr Opin Obstet Gynecol. 2011:151-57

20. Abdel-Meguid TA, Al-Sayyad A, Tayib A, Farsi HM. Does varicocele repair improve male infertility? An evidence-based perspective from a randomized, controlled trial. European urology. 2011;59:455-61.

21. Najari BB, Introna L, Paduch DA. Improvements in patientreported sexual function after microsurgical varicocelectomy. Urology. 2017;110:104-9. 